\title{
CARACTERIZAÇÃO DE IOGURTES ELABORADOS COM PROBIÓTICOS E FIBRA SOLÚVEL
}

\section{CHARACTERIZATION OF YOGURTS ELABORATED WITH PROBIOTICS AND SOLUBLE FIBER}

\author{
Claudia Capitani ${ }^{1}$; Fabiane Antonia Dullius Hauschild ${ }^{2}$; Camila Juliana Friedrich ${ }^{3}$; Daniel Neutzling Lehn ${ }^{4}$; \\ Claucia Fernanda Volken de Souza ${ }^{5}$ \\ ${ }^{1}$ Centro Universitário UNIVATES - Lajeado - Brasil claudiacapitani.f@ gmail.com \\ ${ }^{2}$ Centro Universitário UNIVATES - Lajeado - Brasil fabianedullius@ bol.com.br \\ ${ }^{3}$ Centro Universitário UNIVATES - Lajeado - Brasil camilajulianafredrich@ hotmail.com \\ ${ }^{4}$ Centro Universitário UNIVATES - Lajeado - Brasil lehn@univates.br \\ ${ }^{5}$ Centro Universitário UNIVATES - Lajeado - Brasil claucia@ univates.br
}

\section{Resumo}

Atualmente o consumo de alimentos funcionais passou a fazer parte do dia a dia. Os alimentos lácteos funcionais destacam-se por terem alto valor nutricional, além de proteínas de elevado valor biológico. $O$ estilo de vida, cada vez mais acelerado, está levando os consumidores a incluir o iogurte na sua alimentação. Nesse contexto, o objetivo desse trabalho foi avaliar as características de iogurtes obtidos empregando culturas probióticas de Lactobacillus acidophilus $e$ Bifidobacterium spp. e uma fibra prebiótica, a polidextrose. Foram elaboradas 27 amostras de iogurte, em diferentes condições do processo, tais como concentração da cultura láctica, da fibra solúvel prebiótica e de leite em pó, e da temperatura de fermentação. Essas amostras foram submetidas às análises físico-químicas, microbiológica e sensorial no $1^{\circ}$ e $14^{o}$ dia de fabricação. Somente uma amostra apresentou um teor de proteínas em desacordo com o limite mínimo estabelecido pela legislação brasileira. A acidez de todas as amostras estava conforme o preconizado pela legislação. Os iogurtes elaborados se enquadram na categoria de integral $e$ parcialmente desnatado. Os produtos apresentaram contagens de bactérias lácticas superiores a $10^{8} \mathrm{UFC} / \mathrm{mL}$. A partir das condições de elaboração empregadas é possível obter um iogurte funcional de qualidade, sob os aspectos físico-químicos e sensoriais.

Palavras-chave: iogurte; alimento funcional; probióticos; prebióticos.

\section{Introdução}

O Brasil é o sexto maior produtor de leite no mundo (MILKPOINT, 2011). O alto volume de produção confere à atividade leiteira uma grande importância socioeconômica, gerando empregos, renda e tributos (ÁLVARES et al., 2002). A partir do leite muitos derivados podem ser elaborados, tais como iogurte, bebida láctea, queijo, doce de leite e manteiga, agregando valor ao 
produto. Uma das principais fontes de cálcio e proteínas na alimentação da população brasileira é o leite, incluindo seus derivados (BEHMER, 1995).

O iogurte é um produto lácteo fermentado espesso e levemente ácido (FERREIRA, 1992). Reconhecido pelas suas propriedades sensoriais, nutricionais e terapêuticas, é considerado um alimento tradicional (GONZALEZ et al., 2011). Como é fermentado por bactérias lácticas, apresenta maior valor nutricional do que o leite em função da digestão parcial de proteínas, gorduras, carboidratos, e pelo elevado teor de vitaminas do complexo B (DEMIATE et al., 1994). As características do produto podem variar de acordo com o tipo de iogurte e com o leite empregado em sua fabricação. Com relação ao teor de gordura, pode ser usado leite integral, semidesnatado ou totalmente desnatado (FERREIRA, 1992).

O processo de fabricação do iogurte envolve inicialmente a etapa de mistura dos ingredientes adicionados - açúcar, leite em pó, sabor - ao leite, seguida de padronização, homogeneização e pasteurização. Neste tratamento térmico ocorre o aquecimento para eliminação de micro-organismos degradadores, que podem causar efeitos indesejáveis ao produto, ou patogênicos, que podem ser prejudiciais a saúde humana. Após o processo de pasteurização, a mistura é resfriada até $40-45^{\circ} \mathrm{C}$. A seguir, a cultura iniciadora de bactérias lácticas é adicionada, promovendo a fermentação até a acidez desejada. Depois a mistura é resfriada até $4{ }^{\circ} \mathrm{C}$, o produto é envasado nas embalagens específicas, e armazenado sob baixa temperatura $\left(2\right.$ a $\left.5{ }^{\circ} \mathrm{C}\right)$ para que mantenha suas características iniciais por mais tempo (RODAS et al., 2001; FERREIRA, 1992).

O estilo de vida, cada vez mais acelerado está levando os consumidores a incluir o iogurte na sua alimentação, por ser um alimento prático, e também pelos benefícios oferecidos a saúde. A indústria alimentícia nos últimos anos intensificou a procura por alimentos que promovam saúde e melhor qualidade de vida através de pesquisa e desenvolvimento de produtos com diferentes ingredientes e componentes naturais. Dentre estes se destacam os alimentos denominados funcionais (OLIVEIRA, 2009).

Alimentos funcionais são aqueles que além de fornecer nutrientes básicos, favorecem a saúde. Os alimentos lácteos funcionais apresentam proteínas de alto valor biológico, conferindolhes excelente qualidade nutricional. O mercado de alimentos funcionais apresenta crescimento anual de 15 a 20\%, e as indústrias de produtos lácteos contribuem com um expressivo volume de produção desse tipo de alimento (OLIVEIRA, 2009; OLIVEIRA et al., 2002; SAAD, 2006; SANDERS, 1998). Embora o iogurte seja um alimento funcional por ser uma fonte de cálcio, pesquisas recentes têm estudado os efeitos de outros componentes adicionados aos produtos lácteos fermentados, os probióticos e prebióticos (OLIVEIRA, 2009; TORRES, 2001). 
Conforme a resolução $\mathrm{RDC}^{\circ}{ }^{2}$, de 7 de janeiro de 2002, probióticos são micro-organismos vivos capazes de melhorar o equilíbrio microbiano intestinal produzindo efeitos benéficos à saúde do indivíduo (BRASIL, 2002). As bactérias do gênero Lactobacillus e Bifidobacterium são as mais utilizadas como probióticos (GOMES e MALCATA, 1999).

Os prebióticos são ingredientes alimentares não digeríveis que atuam de forma benéfica sobre o organismo humano, através da proliferação seletiva ou da atividade limitada de bactérias presentes no cólon (GIBSON e ROBERFROID, 1995). Entre estes se destaca a fibra solúvel polidextrose, polímero formado por moléculas de glicose, e seu consumo auxilia na modulação de glicose e na redução de colesterol no sangue (CHANDALIA et al., 2000).

Dado o exposto, o presente estudo teve como objetivo elaborar iogurtes com adição de ingredientes funcionais probióticos e prebiótico sob diferentes condições de processamento (concentração da cultura láctica iniciadora, temperatura de fermentação e concentração de ingredientes) avaliando as características físico-químicas, microbiológica e sensorial dos produtos obtidos.

\section{Material e Métodos}

\section{Material}

Para a realização do presente trabalho foram utilizados como ingredientes nas formulações de iogurte propostas os seguintes componentes:

Leite integral (3\%) UHT em sacos plásticos doado pela Laticínios Mimi (Usina de Beneficiamento Cooperativa Languiru Ltda, Teutônia, RS, Brasil).

Fibra solúvel polidextrose doada pela empresa Bremil (Bremil - Indústria de Produtos Alimentícios Ltda, Arroio do Meio, RS, Brasil).

Bactérias lácticas Lactobacillus acidophilus HOWARU DOPHILUS, Bifidobacterium HOWARU BIFIDO, e cultura mista de Lactobacillus delbrueckii subsp. bulgaricus e Streptococcus thermophilus YO-MIX YOGURT CULTURES doadas pela empresa Danisco (Danisco Brasil Ltda, Cotia, SP, Brasil).

Leite em pó comercial integral (3\%) (Elegê, BRF - Brasil Foods SA, Teutônia, RS, Brasil), açúcar refinado comercial, corante em pó Vermelho Rosa SL 10311 (Aromax Indústria e Comércio Ltda, Pindamonhangaba, SP, Brasil) e essência sabor morango (Mix Indústria de Produtos Alimentícios Ltda, São Bernardo do Campo, SP, Brasil), todos adquiridos no comércio local da cidade de Lajeado, RS. 


\section{Métodos}

\section{Planejamento Experimental}

Para avaliação do efeito das diferentes condições de processamento sobre as características dos iogurtes com culturas probióticas e acrescidos de prebiótico foi empregado um delineamento fatorial completo $2^{4}$, com 4 variáveis independentes em dois níveis eqüidistantes $(-1$ e +1$)$, três repetições no ponto central (nível 0) e acrescido de 8 pontos axiais $\left(-\alpha \mathrm{e}+\alpha\right.$ ), onde $\alpha= \pm\left(2^{n}\right)^{1 / 4}$, sendo $n$ o número de variáveis independentes.

Os níveis avaliados das variáveis independentes: concentração de leite em pó, concentração de polidextrose, concentração de cultura láctica iniciadora e temperatura de fermentação encontramse na Tabela 1. O intervalo de estudo destas variáveis foi definido com base em dados apresentados na literatura (KRISTO et al., 2003a; KRISTO et al., 2003b).

Tabela 1 - Níveis codificados e reais das variáveis independentes do planejamento experimental

\begin{tabular}{cccccc}
\hline Variáveis independentes & \multicolumn{5}{c}{ Níveis } \\
\cline { 2 - 6 } & $\mathbf{- 2}$ & $\mathbf{- 1}$ & $\mathbf{0}$ & $\mathbf{+ 1}$ & $\mathbf{+ 2}$ \\
\hline Concentração de leite em pó $(\% \mathrm{~m} / \mathrm{v})$ & 0 & 2,5 & 5 & 7,5 & 10 \\
Concentração de polidextrose $(\% \mathrm{~m} / \mathrm{v})$ & 1 & 3,25 & 5,5 & 7,75 & 10 \\
Concentração de cultura láctica iniciadora $(\% \mathrm{v} / \mathrm{v})$ & 1 & 2,25 & 3,5 & 4,75 & 6 \\
Temperatura de fermentação $\left({ }^{\circ} \mathrm{C}\right)$ & 35 & 37,5 & 40 & 42,5 & 45 \\
\hline
\end{tabular}

A Tabela 2 apresenta o número total de ensaios, correspondente as amostras de iogurte elaboradas, estabelecido pelo planejamento experimental, com as variáveis nos níveis codificados e seus valores reais.

\section{Preparação da cultura láctica iniciadora}

As três culturas lácticas comerciais liofilizadas foram misturadas em igual proporção $(1 \mathrm{~g}$ de cada) de forma asséptica, inoculadas em 1L de leite integral UHT, que foi homogeneizado e incubado a $37^{\circ} \mathrm{C}$ por 1 hora.

A Figura 1 apresenta o fluxograma das etapas da preparação da cultura láctica iniciadora.

Figura 1 - Preparação da cultura láctica iniciadora

Pesar sob condições assépticas as culturas lácticas

Adicionar $1 \mathrm{~g}$ de Lactobacillus acidophilus $+1 \mathrm{~g}$ de Bifidobacterium $+1 \mathrm{~g}$ de cultura mista de Lactobacillus delbrueckii subsp. bulgaricus e Streptococcus thermophilus em 1 L de leite integral UHT (em frasco estéril) 
Tabela 2 - Matriz do planejamento experimental empregado na elaboração das amostras de iogurtes

\begin{tabular}{|c|c|c|c|c|c|c|c|c|}
\hline Amostra & $\begin{array}{c}\text { Concentração } \\
\text { de leite } \\
\text { em pó }\end{array}$ & $\begin{array}{l}\text { Concentração } \\
\text { de polidextrose }\end{array}$ & $\begin{array}{l}\text { Concentração } \\
\text { de cultura } \\
\text { láctica } \\
\text { iniciadora }\end{array}$ & $\begin{array}{c}\text { Temperatura } \\
\text { de } \\
\text { fermentação }\end{array}$ & $\begin{array}{c}\text { Concentração } \\
\text { de leite em pó } \\
(\% \mathrm{~m} / \mathrm{v})\end{array}$ & $\begin{array}{l}\text { Concentração } \\
\text { de polidextrose } \\
(\% \mathrm{~m} / \mathrm{v})\end{array}$ & $\begin{array}{c}\text { Concentração } \\
\text { de cultura } \\
\text { láctica } \\
(\% \mathrm{v} / \mathrm{v})\end{array}$ & $\begin{array}{c}\text { Temperatura } \\
\text { de } \\
\text { fermentação } \\
\left({ }^{\circ} \mathrm{C}\right)\end{array}$ \\
\hline 1 & -1 & -1 & -1 & -1 & 2,5 & 3,25 & 2,25 & 37,5 \\
\hline 2 & -1 & -1 & -1 & 1 & 2,5 & 3,25 & 2,25 & 42,5 \\
\hline 3 & -1 & -1 & 1 & -1 & 2,5 & 3,25 & 4,75 & 37,5 \\
\hline 4 & -1 & -1 & 1 & 1 & 2,5 & 3,25 & 4,75 & 42,5 \\
\hline 5 & -1 & 1 & -1 & -1 & 2,5 & 7,75 & 2,25 & 37,5 \\
\hline 7 & -1 & 1 & 1 & -1 & 2,5 & 7,75 & 4,75 & 37,5 \\
\hline 8 & -1 & 1 & 1 & 1 & 2,5 & 7,75 & 4,75 & 42,5 \\
\hline 9 & 1 & -1 & -1 & -1 & 7,5 & 3,25 & 2,25 & 37,5 \\
\hline 10 & 1 & -1 & -1 & 1 & 7,5 & 3,25 & 2,25 & 42,5 \\
\hline 11 & 1 & -1 & 1 & -1 & 7,5 & 3,25 & 4,75 & 37,5 \\
\hline 12 & 1 & -1 & 1 & 1 & 7,5 & 3,25 & 4,75 & 42,5 \\
\hline 13 & 1 & 1 & -1 & -1 & 7,5 & 7,75 & 2,25 & 37,5 \\
\hline 14 & 1 & 1 & -1 & 1 & 7,5 & 7,75 & 2,25 & 42,5 \\
\hline 15 & 1 & 1 & 1 & -1 & 7,5 & 7,75 & 4,75 & 37,5 \\
\hline 17 & -2 & 0 & 0 & 0 & 0 & 5,5 & 3,5 & 40 \\
\hline 18 & +2 & 0 & 0 & 0 & 10 & 5,5 & 3,5 & 40 \\
\hline 19 & 0 & -2 & 0 & 0 & 5 & 1 & 3,5 & 40 \\
\hline 20 & 0 & +2 & 0 & 0 & 5 & 10 & 3,5 & 40 \\
\hline 21 & 0 & 0 & -2 & 0 & 5 & 5,5 & 1 & 40 \\
\hline 22 & 0 & 0 & +2 & 0 & 5 & 5,5 & 6 & 40 \\
\hline 23 & 0 & 0 & 0 & -2 & 5 & 5,5 & 3,5 & 35 \\
\hline 24 & 0 & 0 & 0 & +2 & 5 & 5,5 & 3,5 & 45 \\
\hline 25 & 0 & 0 & 0 & 0 & 5 & 5,5 & 3,5 & 40 \\
\hline 26 & 0 & 0 & 0 & 0 & 5 & 5,5 & 3,5 & 40 \\
\hline 27 & 0 & 0 & 0 & 0 & 5 & 5,5 & 3,5 & 40 \\
\hline
\end{tabular}




\section{Preparação do iogurte}

Para cada ensaio (Tabela 2) foram adicionados em um recipiente estéril 1,5 L de leite integral UHT, $12 \%(\mathrm{~m} / \mathrm{v})$ de açúcar refinado, leite em pó e fibra prebiótica polidextrose, nas proporções estabelecidas pelo planejamento experimental.

As misturas foram homogeneizadas e aquecidas até $85^{\circ} \mathrm{C}$ e mantidas por 15 minutos em banho termostatizado, sendo a seguir resfriadas em banho de gelo até atingir $35^{\circ} \mathrm{C}$. Após foi adicionada em condições assépticas a cultura láctica iniciadora, nos níveis apresentados na Tabela 2. A Figura 2 apresenta o fluxograma das etapas da fabricação dos iogurtes.

Figura 2 - Fluxograma das etapas de fabricação dos iogurtes

\begin{tabular}{|c|}
\hline $\begin{array}{c}\text { Transferir 1,5 L de leite UHT integral } \\
\text { para erlenmeyer de } 2 \text { L estéril }\end{array}$ \\
\hline $\mathbf{\nabla}$
\end{tabular}

\begin{tabular}{|c|}
\hline Adicionar $12 \%(\mathrm{~m} / \mathrm{v})$ de açúcar refinado \\
\hline $\boldsymbol{\nabla}$ \\
Adicionar o leite em pó \\
(quantidade definida no planejamento) \\
\hline
\end{tabular}

\section{Adicionar a polidextrose}

(quantidade definida no planejamento)

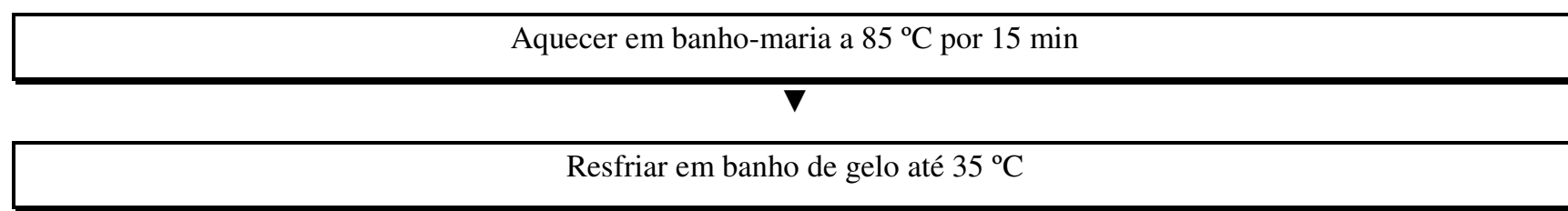

Adicionar a cultura láctica iniciadora

(quantidade definida no planejamento)

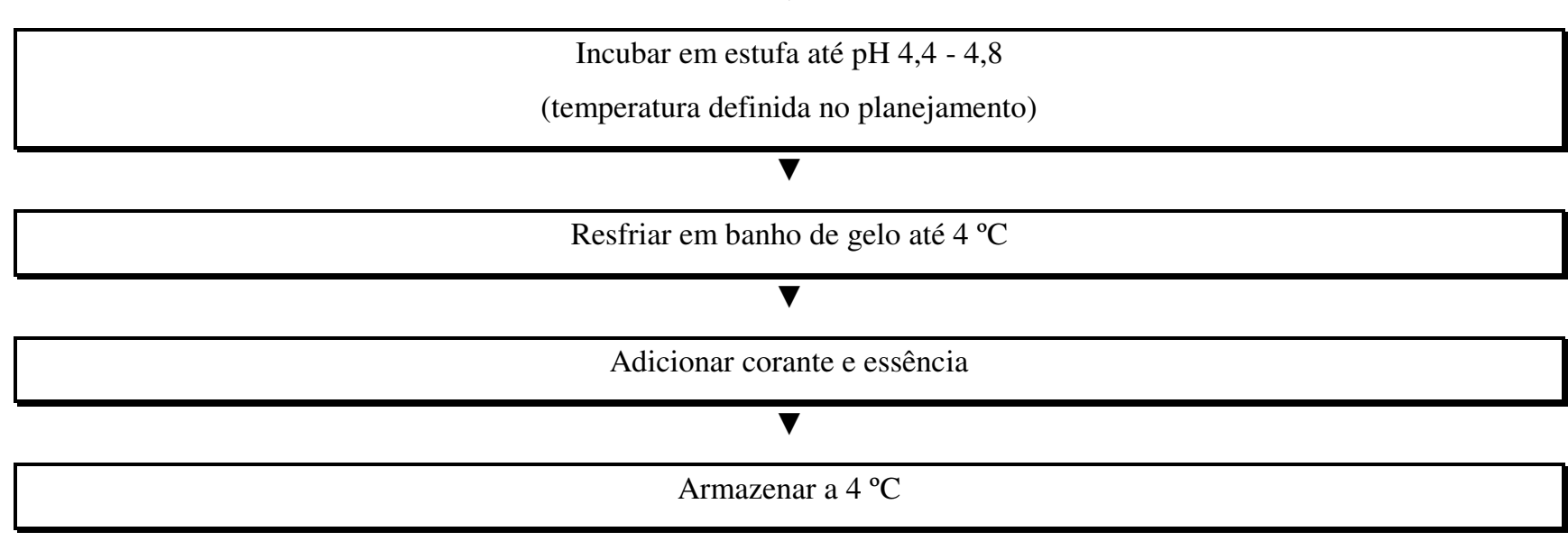


Em seguida as amostras foram incubadas na temperatura de fermentação (Tabela 2) até atingir um $\mathrm{pH}$ entre 4,4 - 4,8. Terminada a fermentação, a temperatura foi reduzida em banho de gelo até $4{ }^{\circ} \mathrm{C}$, e foram adicionados $0,3 \mathrm{~mL}$ de essência e $0,3 \mathrm{~g}$ de corante. Os iogurtes foram embalados em copos plásticos de polietileno e armazenados em refrigeração à temperatura de aproximadamente $4{ }^{\circ} \mathrm{C}$.

As análises físico-químicas, microbiológica e sensorial foram realizadas no $1^{\circ}$ e no $14^{\circ}$ dia após a fabricação.

\section{Análises físico-químicas}

Para a caracterização físico-química dos iogurtes foram utilizados os seguintes procedimentos: umidade pela secagem em estufa a $105^{\circ} \mathrm{C}$ até peso constante, lipídios pelo método do butirômetro de Gerber, $\mathrm{pH}$ utilizando pHmetro digital, acidez por titulação com $\mathrm{NaOH}$ e fenolftaleína como indicador, e proteínas através da determinação do teor de nitrogênio total pelo método de micro-Kjeldahl e convertido em proteína bruta pelo fator 6,38, conforme metodologias do Ministério da Agricultura, Pecuária e Abastecimento (BRASIL, 2006). As cinzas foram determinadas por incineração em forno mufla a $550{ }^{\circ} \mathrm{C}$ (IAL, 2005). $\mathrm{O}$ teor de carboidratos totais foi determinado pelo cálculo da diferença de 100 gramas de amostra e a soma total dos valores encontrados para os componentes: umidade, lipídios, proteínas, e cinzas. Todas as análises foram realizadas em triplicata.

\section{Análise microbiológica}

A contagem de bactérias lácticas viáveis dos iogurtes foi realizada de acordo com a metodologia proposta por Kempka et al. (2008). Alíquotas de $10 \mathrm{~mL}$ das amostras foram diluídas em $90 \mathrm{~mL}$ de água peptonada $0,1 \%$, homogeneizadas e submetidas a diluições sucessivas em $9 \mathrm{~mL}$ de água peptonada $0,1 \%$. Posteriormente foi realizada a semeadura em profundidade das diluições $10^{-6}$ a $10^{-8}$ em meio de cultura Ágar MRS (Man, Rogosa \& Sharpe) em duplicata, seguida da adição de uma sobrecamada do mesmo meio de cultivo. As placas invertidas foram incubadas a $37{ }^{\circ} \mathrm{C}$ por $72 \mathrm{~h}$ em jarra de anaerobiose, contendo o gerador de anaerobiose ANAEROBAC (Probac do Brasil Produtos Bacteriológicos Ltda, São Paulo, SP, Brasil).

\section{Avaliação sensorial}

A avaliação sensorial dos iogurtes para determinar a impressão global sobre o produto foi realizada no Laboratório de Análise Sensorial em cabines individuais sob luz branca e à temperatura ambiente, com as amostras dispostas em copos plásticos descartáveis de $50 \mathrm{~mL}$ e servidas em bandejas de aço inoxidável. As amostras em porções padronizadas (aproximadamente $10 \mathrm{~mL}$ ) foram codificadas com números aleatórios de 3 dígitos e apresentadas aos provadores de forma balanceada e aleatorizada. Junto com as amostras, foi servida água mineral à temperatura ambiente para 
limpeza do palato e a ficha do teste contendo uma escala hedônica estruturada de 9 pontos, variando de 1 “desgostei muitíssimo" à 9 "gostei muitíssimo". A análise sensorial, através do teste de aceitação, foi realizada por 35 provadores não treinados, recrutados entre os estudantes e colaboradores da Univates, sendo 15 homens e 20 mulheres, com idade entre 20 e 48 anos, os quais avaliaram a preferência em relação ao atributo impressão global.

Somente participaram da análise sensorial os provadores que assinaram o Termo de Consentimento Livre e Esclarecido (TCLE), conforme Resolução 196 nº 96 do Ministério da Saúde (BRASIL, 1996) aprovado pelo Comitê de Ética em Pesquisa (COEP) da Univates sob o registro $\mathrm{n}^{\circ}$ 034/10.

\section{Resultados e Discussão}

As Tabelas 3 e 4 apresentam os resultados das análises físico-químicas das 27 amostras de iogurtes com 1 e 14 dias de fabricação, respectivamente.

Tabela 3 - Resultados das análises físico-químicas dos iogurtes no $1^{\circ}$ dia de fabricação

\begin{tabular}{|c|c|c|c|c|c|c|c|}
\hline Amostra & $\begin{array}{c}\text { Umidade } \\
(\%)\end{array}$ & $\begin{array}{c}\text { Proteínas } \\
(\%)\end{array}$ & $\begin{array}{c}\text { Cinzas } \\
(\%)\end{array}$ & $\begin{array}{c}\text { Lipídios } \\
(\%)\end{array}$ & $\mathrm{pH}$ & $\begin{array}{c}\text { Acidez } \\
\text { (\% ácido lático) }\end{array}$ & $\begin{array}{c}\text { Carboidrato } \\
(\%)\end{array}$ \\
\hline 1 & 75,8 & 3,3 & 0,8 & 2,2 & 4,58 & 0,72 & 17,9 \\
\hline 2 & 74,4 & 4,1 & 0,7 & 3,3 & 4,57 & 0,77 & 17,4 \\
\hline 3 & 76,3 & 3,3 & 0,8 & 2,4 & 4,63 & 0,66 & 17,2 \\
\hline 4 & 75,8 & 3,2 & 0,8 & 2,1 & 4,64 & 0,69 & 18,1 \\
\hline 5 & 73,0 & 3,2 & 0,8 & 2,2 & 4,62 & 0,64 & 20,8 \\
\hline 6 & 74,5 & 3,1 & 0,8 & 2,3 & 4,83 & 0,69 & 19,3 \\
\hline 7 & 73,3 & 3,2 & 0,8 & 2,2 & 4,63 & 0,61 & 20,6 \\
\hline 8 & 73,0 & 3,1 & 0,8 & 2,2 & 4,83 & 0,65 & 20,9 \\
\hline 9 & 73,5 & 4,2 & 1,0 & 3,0 & 4,58 & 0,80 & 18,2 \\
\hline 10 & 72,8 & 4,3 & 1,0 & 3,3 & 4,73 & 0,69 & 18,4 \\
\hline 11 & 73,8 & 4,2 & 1,0 & 3,1 & 4,64 & 0,78 & 17,9 \\
\hline 12 & 73,4 & 4,1 & 1,0 & 3,1 & 4,57 & 0,74 & 18,4 \\
\hline 13 & 71,1 & 3,9 & 1,0 & 3,2 & 4,70 & 0,72 & 20,7 \\
\hline 14 & 70,6 & 4,0 & 0,9 & 3,4 & 4,79 & 0,70 & 21,0 \\
\hline 15 & 72,0 & 4,0 & 1,0 & 3,0 & 4,61 & 0,75 & 20,0 \\
\hline 16 & 69,9 & 3,9 & 0,9 & 3,2 & 4,70 & 0,68 & 22,0 \\
\hline 17 & 75,5 & 2,9 & 0,7 & 1,5 & 4,69 & 0,60 & 19,4 \\
\hline 18 & 70,4 & 5,1 & 1,0 & 2,6 & 4,68 & 0,83 & 20,7 \\
\hline 19 & 76,1 & 3,9 & 0,9 & 2,4 & 4,69 & 0,79 & 16,6 \\
\hline 20 & 70,3 & 3,8 & 0,8 & 2,4 & 4,74 & 0,69 & 22,7 \\
\hline 21 & 73,0 & 3,6 & 0,9 & 3,0 & 4,46 & 0,82 & 19,5 \\
\hline 22 & 73,6 & 3,6 & 0,9 & 2,5 & 4,74 & 0,74 & 19,3 \\
\hline 23 & 73,3 & 3,6 & 0,9 & 3,2 & 4,75 & 0,70 & 19,0 \\
\hline 24 & 73,4 & 3,7 & 0,9 & 2,5 & 4,50 & 0,81 & 19,6 \\
\hline 25 & 72,7 & 4,1 & 0,9 & 2,5 & 4,78 & 0,65 & 19,8 \\
\hline 26 & 73,7 & 3,2 & 0,9 & 3,0 & 4,42 & 0,86 & 19,2 \\
\hline 27 & 73,1 & 3,9 & 0,9 & 2,2 & 4,83 & 0,71 & 19,8 \\
\hline
\end{tabular}


Em relação ao teor de umidade, observou-se uma variação de 69,9 a 76,3\% (Tabela 3) no $1^{\circ}$ dia de fabricação e de 69,8 a 76,7\% (Tabela 4) no $14^{\circ}$ dia de fabricação. Esses valores são semelhantes aos de outros trabalhos descritos na literatura. Silva (2007) elaborou amostras de iogurte com diferentes concentrações de culturas lácticas e encontrou teores de umidade entre 78,01 a 78,04\%, enquanto Rensis e Souza (2008), na avaliação de três amostras de iogurte elaboradas com leite integral, leite desnatado com $2 \%$ de inulina e leite desnatado com $2 \%$ de oligofrutose encontraram teores de 82,$88 ; 83,96$ e $82,91 \%$, respectivamente.

Tabela 4 - Resultados das análises físico-químicas dos iogurtes no $14^{\circ}$ dia de fabricação

\begin{tabular}{|c|c|c|c|c|c|c|c|}
\hline Amostra & $\begin{array}{c}\text { Umidade } \\
(\%)\end{array}$ & $\begin{array}{c}\text { Proteína } \\
(\%)\end{array}$ & $\begin{array}{c}\text { Cinzas } \\
(\%)\end{array}$ & $\begin{array}{c}\text { Lipídios } \\
(\%)\end{array}$ & pH & $\begin{array}{l}\text { Acidez } \\
\text { (\% ácido }\end{array}$ & $\begin{array}{c}\text { Carboidratos } \\
(\%)\end{array}$ \\
\hline 1 & 76,0 & 3,2 & 0,7 & 3,2 & 4,43 & 0,74 & 16,8 \\
\hline 2 & 76,4 & 3,0 & 0,8 & 3,2 & 4,48 & 0,72 & 16,6 \\
\hline 3 & 76,2 & 3,6 & 0,7 & 2,5 & 4,51 & 0,73 & 16,9 \\
\hline 4 & 76,7 & 3,3 & 0,8 & 3,2 & 4,60 & 0,71 & 16,0 \\
\hline 5 & 73,1 & 3,1 & 0,8 & 2,0 & 4,42 & 0,67 & 21,0 \\
\hline 6 & 73,7 & 3,3 & 0,8 & 3,1 & 4,64 & 0,69 & 19,1 \\
\hline 7 & 75,3 & 3,0 & 0,8 & 2,4 & 4,50 & 0,69 & 18,4 \\
\hline 8 & 73,9 & 3,3 & 0,8 & 3,1 & 4,59 & 0,72 & 19,0 \\
\hline 9 & 73,3 & 4,2 & 0,9 & 3,6 & 4,52 & 0,91 & 17,8 \\
\hline 10 & 74,0 & 4,6 & 1,0 & 4,1 & 4,62 & 0,84 & 16,3 \\
\hline 11 & 73,6 & 4,2 & 1,0 & 3,0 & 4,56 & 0,85 & 18,1 \\
\hline 12 & 74,0 & 4,1 & 1,0 & 4,1 & 4,48 & 0,87 & 16,8 \\
\hline 13 & 71,2 & 4,0 & 1,0 & 3,2 & 4,62 & 0,80 & 20,6 \\
\hline 14 & 71,1 & 4,1 & 1,0 & 3,9 & 4,62 & 0,88 & 19,9 \\
\hline 15 & 71,2 & 4,1 & 1,0 & 3,8 & 4,59 & 0,80 & 19,8 \\
\hline 16 & 71,1 & 4,0 & 0,9 & 3,9 & 4,66 & 0,83 & 20,0 \\
\hline 17 & 74,9 & 2,6 & 0,6 & 1,9 & 4,59 & 0,68 & 19,9 \\
\hline 18 & 69,9 & 4,4 & 1,0 & 3,4 & 4,67 & 1,02 & 21,3 \\
\hline 19 & 75,2 & 3,6 & 0,8 & 2,7 & 4,67 & 0,86 & 17,7 \\
\hline 20 & 69,8 & 3,6 & 0,8 & 2,7 & 4,68 & 0,81 & 23,0 \\
\hline 21 & 72,5 & 3,6 & 0,9 & 2,7 & 4,29 & 0,85 & 20,3 \\
\hline 22 & 72,7 & 3,6 & 0,9 & 2,7 & 4,68 & 0,82 & 20,1 \\
\hline 23 & 73,3 & 3,6 & 0,9 & 2,6 & 4,44 & 0,78 & 19,6 \\
\hline 24 & 72,9 & 3,6 & 0,8 & 2,6 & 4,32 & 0,86 & 20,0 \\
\hline 25 & 72,4 & 3,7 & 0,8 & 2,6 & 4,79 & 0,85 & 20,4 \\
\hline 26 & 72,4 & 3,6 & 0,8 & 2,6 & 4,23 & 0,86 & 20,5 \\
\hline 27 & 72,2 & 3,6 & 0,8 & 2,5 & 4,74 & 0,85 & 20,8 \\
\hline
\end{tabular}

Os teores de proteínas nos iogurtes no $1^{\circ}$ e $14^{\circ}$ dia apresentaram uma variação de 2,9 a 5,1\% e 2,6 a 4,6\%, respectivamente. Os menores teores de proteínas correspondem à amostra 17, na qual não foi adicionado leite em pó. Com relação à amostra 18, com maior teor de leite em pó, a mesma apresentou maior teor de proteínas no $1^{\circ}$ dia de fabricação, e uma das maiores concentrações $(4,41 \%)$ no $14^{\circ}$ dia. A adição de leite em pó normalmente aumenta o teor de sólidos, elevando o 
conteúdo protéico do iogurte (DEETH e TAMINE, 1981). Torres et al. (2000), durante a avaliação da composição centesimal de produtos de origem animal verificaram um teor de proteínas de $25,68 \%$ no leite em pó. Cunha et al. (2008) encontraram 2,80\% de proteínas em iogurtes adicionados de Lactobacillus acidophilus, Bifidobacterium e Streptococcus thermophilus, enquanto Fuchs et al. (2006) determinaram 3,10\% de proteínas em iogurtes simbióticos, valores semelhantes aos encontrados neste estudo. Conforme a Resolução $n^{\circ} 5$ do Ministério da Agricultura, Pecuária e Abastecimento (BRASIL, 2000), o iogurte deve apresentar no mínimo 2,9 g/100 g de proteína láctea. Apenas a amostra 17 apresentou valor inferior.

As amostras de iogurte apresentaram valores de cinzas variando de 0,7 a $1,0 \%$ no $1^{\circ}$ dia (Tabela 3) e 0,6 a 1,0\% no $14^{\circ}$ dia (Tabela 4) de fabricação. A maior parte das amostras apresentou teor de cinzas em torno de $0,8 \%$, valor semelhante ao encontrado no leite, conforme Tronco (2008). As amostras 17 e 18 apresentaram o maior e o menor teor de cinzas, respectivamente, no $1^{\circ}$ e $14^{\circ}$ dia de armazenamento. Essa diferença pode ser justificada pela adição do leite em pó. Nas formulações de iogurtes com diferentes concentrações de culturas probióticas desenvolvidas por Silva (2007), foram identificados teores de cinzas que variaram de 0,73 a $0,82 \%$, enquanto Cunha et al. (2008) em iogurte probiótico obtiveram $0,60 \%$, valores próximos a maioria das amostras elaboradas neste trabalho.

A porcentagem de lipídios no $1^{\circ}$ e no $14^{\circ}$ dia (Tabelas 3 e 4) variou de 1,5 a 3,4\% e 1,9 a $4,1 \%$, respectivamente. Novamente, esta variação pode ter sido influenciada pela adição de leite em pó. Segundo a legislação (BRASIL, 2000), o iogurte pode ser considerado integral quando seu teor de lipídios for de 3,0 a 5,9\%, parcialmente desnatado de 0,6 a 2,9\% e desnatado quando possuir no máximo $0,5 \%$. Portanto, os iogurtes elaborados se enquadram na categoria de integral e parcialmente desnatado. Outros trabalhos envolvendo análise de iogurtes probióticos encontraram teores semelhantes aos deste estudo, como Cunha et al. (2008), que encontraram resultado de 3,03\%, e Silva (2007), que utilizando culturas tradicionais (S. thermophilus e L. bulgaricus) e probióticos (L. acidophilus e Bifidobacterium spp.), observou teores de lípidios entre 3,12 e 3,15\%, além de Pereira (2002) que, ao analisar iogurtes elaborados com leite de baixo teor de lactose, encontrou teores de lipídios entre 3,92 a 4,07\%.

No $1^{\circ}$ dia de fabricação os valores de $\mathrm{pH}$ dos iogurtes variaram de 4,42 a 4,83 (Tabela 3) e no $14^{\circ}$ dia variaram de 4,23 a 4,79 (Tabela 4). Comparando os valores de $\mathrm{pH}$ de cada amostra entre o $1^{\circ}$ e o $14^{\circ}$ dia de armazenamento observou-se uma redução. Esse comportamento dos valores de pH para amostras de iogurtes probióticos também foi observada por Oliveira et al. (2002) e Pereira (2002). Os primeiros autores estudaram a viabilidade de bactérias lácticas do iogurte e de bactérias probióticas do leite fermentado. Pereira (2002), analisando o pH dos iogurtes elaborados com leite 
integral ultrafiltrado com 4,5\% de lactose e probióticos, observou uma variação de 4,57 a 4,24 no $\mathrm{pH}$ das amostras entre o $1^{\circ}$ e o $14^{\circ}$ dia de armazenamento, respectivamente, enquanto em iogurtes elaborados com leite integral diafiltrado com 1,7\% de lactose e probióticos, verificou uma variação de 4,66 a 4,40 no mesmo período.

As Tabelas 3 e 4 descrevem a variação da acidez (expressa em g de ácido láctico/100 g de produto) no $1^{\circ}$ e $14^{\circ}$ dia de fabricação. Os valores variaram entre 0,60 a $0,86 \mathrm{~g}$ de ácido láctico/100 g para o $1^{\circ}$ dia, e no $14^{\circ}$ dia houve uma variação de 0,67 a $1,02 \mathrm{~g}$ de ácido láctico/100 g. Conforme a Resolução $\mathrm{n}^{\circ} 5$ do Ministério da Agricultura, Pecuária e Abastecimento (BRASIL, 2000), os valores de acidez devem ser de no mínimo 0,6 g de ácido láctico/100 g de produto e de no máximo 1,5 g de ácido láctico/100 g de produto. Portanto, todas as amostras de iogurte elaboradas estão de acordo com os padrões estabelecidos pela legislação. A acidez é um valor importante na determinação da qualidade do iogurte, pois valores elevados podem estar relacionados à falta de controle de temperatura durante o armazenamento (MARTIN, 2002). Os teores de acidez encontrados por Cunha et al. (2008), 0,70\% de ácido láctico, e Becker (2009), 0,71 a 0,78\% de ácido láctico no $1^{\circ}$ dia de armazenamento e 0,85 a $0,94 \%$ de ácido láctico no $28^{\circ}$ dia de armazenamento, foram semelhantes aos resultados obtidos neste trabalho.

Observou-se um aumento da acidez e uma redução do pH das amostras de iogurte durante os 14 dias de armazenamento (Tabelas 3 e 4). Isto ocorre em função da produção contínua de ácidos pelas bactérias lácticas durante o armazenamento. A acidez de iogurtes probióticos tende a aumentar, pois os lactobacilos produzem ácidos e continuam a crescer em pH entre 4,0 e 4,4 (SILVA, 2007; TRONCO, 2008). Hussain et al. (2009) também observaram um aumento da acidez em amostras de iogurtes probióticos.

Os carboidratos apresentaram uma variação de 16,6 a 22,7\% e 16,0 a $23,0 \%$ no $1^{\circ}$ e $14^{\circ}$ dia de fabricação, respectivamente. Essa diferença entre as amostras se justifica principalmente pela adição de fibra prebiótica polidextrose. A amostra 20, na qual foi adicionada a maior concentração de polidextrose $(10 \% \mathrm{~m} / \mathrm{v})$, apresentou o maior teor de carboidratos no $1^{\circ}$ e no $14^{\circ}$ dia de fabricação. Já a amostra 19, na qual foi adicionada apenas $1 \% \mathrm{~m} / \mathrm{v}$ de polidextrose, apresentou o menor teor carboidratos no $1^{\circ}$ dia após a fabricação e um dos menores teores no $14^{\circ}$ dia $(17,7 \%)$. Cunha et al. (2008) elaboraram e analisaram uma amostra de iogurte probiótico, verificando um teor de carboidratos de 13,0\%, valor inferior ao mínimo obtido no presente trabalho, provavelmente porque esse iogurte não foi adicionado de fibra solúvel, dessa forma o único carboidrato presente era a lactose, normalmente encontrada no leite (TRONCO, 2008). Rensis e Souza (2008) determinaram a composição química de iogurtes lights elaborados com leite desnatado e $2 \%$ de inulina ou de oligofrutose. As amostras apresentaram valores de carboidratos de 10,81 e 11,98\%, 
respectivamente, inferiores ao mínimo obtido no presente trabalho. Provavelmente, tal fato deve-se aos diferentes ingredientes empregados nas formulações dos iogurtes. Tais autores utilizaram leite desnatado, ao invés de leite integral, e os iogurtes não foram adicionados de açúcar.

Os valores das contagens de bactérias lácticas viáveis das amostras de iogurtes no $1^{\circ}$ e $14^{\circ}$ dia de armazenamento estão apresentados na Tabela 5.

Tabela 5 - Resultados (UFC/mL) das análises de contagem de bactérias lácticas viáveis no $1^{\circ}$ e $14^{\circ}$ de dia de fabricação

\begin{tabular}{|c|c|c|}
\hline Amostra & $1^{\circ}$ dia & $14^{\circ}$ dia \\
\hline 1 & $1,4 \times 10^{9}$ & $4,6 \times 10^{8}$ \\
\hline 2 & $6,5 \times 10^{8}$ & $1,3 \times 10^{9}$ \\
\hline 3 & $1,1 \times 10^{9}$ & $4,2 \times 10^{8}$ \\
\hline 4 & $3,5 \times 10^{8}$ & $2,7 \times 10^{8}$ \\
\hline 5 & $1,6 \times 10^{9}$ & $5,7 \times 10^{9}$ \\
\hline 6 & $1,5 \times 10^{8}$ & $1,9 \times 10^{9}$ \\
\hline 7 & $2,8 \times 10^{9}$ & $5,7 \times 10^{8}$ \\
\hline 8 & $1,8 \times 10^{9}$ & $8,1 \times 10^{9}$ \\
\hline 9 & $2,6 \times 10^{9}$ & $2,2 \times 10^{9}$ \\
\hline 10 & $1,6 \times 10^{8}$ & $1,3 \times 10^{9}$ \\
\hline 11 & $1,5 \times 10^{9}$ & $2,2 \times 10^{9}$ \\
\hline 12 & $6,5 \times 10^{8}$ & $1,9 \times 10^{9}$ \\
\hline 13 & $8,7 \times 10^{8}$ & $2,2 \times 10^{8}$ \\
\hline 14 & $1,2 \times 10^{8}$ & $1,0 \times 10^{9}$ \\
\hline 15 & $4,4 \times 10^{9}$ & $9,1 \times 10^{8}$ \\
\hline 16 & $4,5 \times 10^{8}$ & $1,2 \times 10^{9}$ \\
\hline 17 & $1,2 \times 10^{9}$ & $1,8 \times 10^{9}$ \\
\hline 18 & $1,1 \times 10^{9}$ & $1,5 \times 10^{9}$ \\
\hline 19 & $1,9 \times 10^{9}$ & $5,5 \times 10^{8}$ \\
\hline 20 & $3,7 \times 10^{8}$ & $4,2 \times 10^{9}$ \\
\hline 21 & $1,7 \times 10^{9}$ & $9,6 \times 10^{8}$ \\
\hline 22 & $4,0 \times 10^{8}$ & $2,4 \times 10^{9}$ \\
\hline 23 & $2,3 \times 10^{9}$ & $1,6 \times 10^{9}$ \\
\hline 24 & $1,2 \times 10^{9}$ & $1,1 \times 10^{9}$ \\
\hline 25 & $1,2 \times 10^{9}$ & $1,9 \times 10^{9}$ \\
\hline 26 & $4,2 \times 10^{9}$ & $1,9 \times 10^{9}$ \\
\hline 27 & $1,2 \times 10^{9}$ & $3,0 \times 10^{9}$ \\
\hline
\end{tabular}

Todas as amostras de iogurte elaboradas apresentaram contagens de bactérias lácticas viáveis superiores a $10^{8} \mathrm{UFC} / \mathrm{mL}$. Conforme a Agência Nacional de Vigilância Sanitária (ANVISA) (BRASIL, 2008), a quantidade mínima de micro-organismos probióticos viáveis deve ser de $10^{8}$ $10^{9} \mathrm{UFC} / \mathrm{mL}$ para que o produto tenha a alegação de funcional.

Os resultados na análise sensorial das amostras de iogurte no $1^{\circ}$ e $14^{\circ}$ dia de fabricação estão apresentados na Tabela 6. 
Tabela 6 - Resultados da análise sensorial das amostras de iogurte no $1^{\circ}$ e $14^{\circ}$ dia de fabricação

\begin{tabular}{|c|c|c|}
\hline Amostra & $1^{\circ}$ dia & $14^{\circ}$ dia \\
\hline 1 & 5,17 & 6,74 \\
\hline 2 & 6,71 & 6,31 \\
\hline 3 & 6,43 & 6,26 \\
\hline 4 & 6,06 & 5,83 \\
\hline 5 & 5,71 & 6,63 \\
\hline 6 & 6,20 & 6,00 \\
\hline 7 & 5,60 & 6,69 \\
\hline 8 & 6,54 & 6,11 \\
\hline 9 & 6,26 & 5,74 \\
\hline 10 & 6,26 & 6,20 \\
\hline 11 & 5,97 & 6,06 \\
\hline 12 & 5,94 & 6,14 \\
\hline 13 & 5,51 & 6,03 \\
\hline 14 & 6,11 & 5,89 \\
\hline 15 & 6,46 & 6,23 \\
\hline 16 & 6,66 & 5,57 \\
\hline 17 & 4,86 & 5,63 \\
\hline 18 & 6,17 & 5,94 \\
\hline 19 & 6,23 & 6,54 \\
\hline 20 & 6,29 & 6,57 \\
\hline 21 & 6,37 & 6,86 \\
\hline 22 & 6,09 & 6,77 \\
\hline 23 & 6,29 & 6,91 \\
\hline 24 & 6,26 & 6,71 \\
\hline 25 & 5,51 & 6,66 \\
\hline 26 & 6,60 & 6,77 \\
\hline 27 & 5,26 & 6,26 \\
\hline
\end{tabular}

As notas atribuídas pelos provadores na avaliação da impressão global dos iogurtes variaram de 4,86 a 6,71 e de 5,57 a 6,91 no $1^{\circ}$ e $14^{\circ}$ dia de fabricação, respectivamente. Verificou-se que a maioria das amostras analisadas em ambos os períodos de fabricação apresentaram aceitação na escala hedônica de 6 (gostei levemente). Trabalhos descritos na literatura mostram variação na aceitação de amostras de iogurte adicionados de ingredientes probióticos e prebióticos. Alguns autores verificaram aceitação superior, enquanto outros, valores inferiores aos do presente trabalho. Oliveira e Jurkiewicz (2009) relataram que as amostras de iogurtes probióticos sem a adição de prebióticos obtiveram uma aceitação de 7,2, enquanto os iogurtes probióticos elaborados com os prebióticos inulina e goma acácia obtiveram uma aceitação entre 7,4 a 7,6, em uma escala hedônica de 9 pontos. Gonzales et al. (2011) avaliaram a aceitação de iogurtes com leite integral sabor pêssego com prebiótico frutooligosacarídeo e com prebiótico frutooligossacarídeo e probiótico Lactobacillus acidophilus (iogurte simbiótico), sendo que o iogurte contendo apenas prebiótico apresentou maior aceitação - 6,2 - que a amostra de iogurte simbiótico - 4,1. 


\title{
4 Conclusão
}

Das vinte e sete amostras de iogurte elaboradas, somente a amostra 17 estava em desacordo aos padrões estabelecidos pela legislação brasileira, uma vez que o teor de proteínas foi abaixo do recomendado. A acidez de todas as amostras estava conforme o preconizado pela legislação. Em relação aos teores de lipídios, os iogurtes elaborados se enquadram na categoria de integral e parcialmente desnatado. Os produtos apresentaram contagens de bactérias lácticas superiores a $10^{8}$ UFC/mL. Os resultados obtidos demonstraram que a partir das condições de elaboração empregadas é possível obter um iogurte funcional, com características probióticas e prebiótica, de qualidade sob os aspectos físico-químicos e sensoriais.

\section{Agradecimentos}

Os autores agradecem as empresas Laticínios Mimi, Bremil e Danisco pela doação do leite, da polidextrose e das bactérias lácticas, respectivamente. A Fundação de Âmparo a Pesquisa do Rio Grande do Sul - FAPERGS e a Secretaria da Ciência, Inovação e Desenvolvimento Tecnológico do Rio Grande do Sul pelos apoios financeiros concedidos a esse trabalho de pesquisa.

\begin{abstract}
Nowadays the consumption of functional foods has become part of our daily life. Functional milky foods having high nutritional value and proteins with high biological value stand out. Lifestyle, faster and faster, is making the consumers include yogurt in their diet. In that context, this present work aims at evaluating the characteristics of yogurts obtained by using probiotic cultures of Lactobacillus acidophilus and Bifidobacterium spp. and a prebiotic fiber, the polydextrose. 27 yogurt samples were elaborated, in different process conditions, such as concentration of the lactic culture; of prebiotic soluble fiber and of powdered milk; and of fermentation temperature. Those samples were submitted to physiochemical, microbiological and sensorial analyses in the 1st and 14th day of production. Only a sample presented a content of proteins in disagreement with the minimum limit established by Brazilian legislation. The acidity of all of the samples was as preconized by law. The elaborated yogurts fit in the category of whole and partially skimmed. The products presented lactic bacteria count higher than $10^{8} \mathrm{CFU} / \mathrm{mL}$. Starting from the employed elaboration conditions it is possible to obtain a functional quality yogurt under the physiochemical and sensorial aspects.
\end{abstract}

Key-words: yogurt; functional food; probiotics; prebiotics.

\section{Referências}

ÁlVARES, J. G.; BERNARDES, P. R.; NETTO, V. N. Políticas para o agronegócio do leite: conquistas e desafios. O agronegócio do leite e políticas públicas para o seu desenvolvimento sustentável, Editora Juiz de Fora: Embrapa Gado de Leite, p. 12, 2002.

BECKER, L. V. Iogurte probiótico com teor reduzido de lactose adicionado de óleo de linhaça. Santa Maria, 2009. 110f. Dissertação (Mestrado em Ciência e Tecnologia dos Alimentos) - Centro de Ciências Rurais - Universidade Federal de Santa Maria.

BEHMER, M. L. A. Tecnologia do leite. 15 ed. São Paulo: Ed. Nobel, 1995. 
BRASIL. Ministério da Saúde. Resolução n 196, de 10 de outubro de 1996. Dispõe sobre diretrizes e normas regulamentadoras de pesquisas envolvendo seres humanos - Conselho Nacional de Saúde do Ministério da Saúde. Diário Oficial da República Federativa do Brasil, Brasília, DF, 16 de outubro de 1996.

BRASIL. Ministério da Agricultura, Pecuária e Abastecimento. Resolução nº 5, de 13 de novembro de 2000. Padrões de identidade e qualidade de leites fermentados. Diário Oficial da República Federativa do Brasil, Brasília, DF, 27 de novembro de 2000 .

BRASIL. Agência Nacional de Vigilância Sanitária. Resolução RDC no 2, de 7 de janeiro de 2002. Regulamento Técnico de Substâncias Bioativas e Probióticos Isolados com Alegação de Propriedades Funcional e ou de Saúde. Diário Oficial da República Federativa do Brasil, Brasília, DF, 17 de julho de 2002.

BRASIL. Ministério da Agricultura, Pecuária e Abastecimento. Instrução Normativa n 68, de 12 de dezembro de 2006. Oficializa os Métodos Analíticos Oficiais Físico-Químicos para Controle de Leite e Produtos Lácteos. Diário Oficial da República Federativa do Brasil, Brasília, DF, 14 de dezembro de 2006.

BRASIL. Agência Nacional de Vigilância Sanitária. Alimentos com Alegações de Propriedades Funcionais e ou de Saúde, Novos Alimentos/Ingredientes, Substâncias Bioativas e Probióticos. IX - Lista de alegações de propriedade funcional aprovadas. Atualizado em Julho de 2008 . Disponível em: <http://www.anvisa.gov.br/alimentos/comissoes/tecno_lista_alega.htm>. Acesso em 15 de nov. 2011.

CHANDAliA, M.; GARG, A.; LUTJOHANN, D.; BERGMANN, K. V.; GRUNDY, S. M.; BRINKLEY, L. J. Beneficial effects of high dietary fiber intake in patients with type 2 diabetes mellitus. New England Journal of Medicine, v. 342, n. 19, p. 1392-1398, 2000. http://dx.doi.org/10.1056/NEJM200005113421903

CUNHA, T. M.; CASTRO, F. P.; BARRETO, P. L. M.; BENEDET, H. D.; PRUDÊNCIO, E. S. Avaliação físicoquímica, microbiológica e reológica de bebida láctea e leite fermentado adicionados de probióticos. Semina: Ciências Agrárias, v. 29, n. 1, p. 103-116, 2008. http://dx.doi.org/10.5433/1679-0359.2008v29n1p103

DEETH, H. C.; TAMINE, A. Y. Yogurt: nutritive and terapeutic aspects. Journal of Food Protection, v. 44, n. 1, p. 78-96, 1981.

DEMIATE, I. M.; OETTERER, M.; WOSIACKI, G. A fermentação como processo de enriquecimento nutricional. Boletim da Sociedade Brasileira de Ciência e Tecnologia de Alimentos, v. 28, n. 2, p.170-181, 1994.

FERREIRA, C. L. L. F. Produtos Lácteos Fermentados: Aspectos Bioquímicos e Tecnológicos. Viçosa: Universidade Federal de Viçosa, 1992.

FUCHS, R. H. B.; TANAMATI, A. A. C.; ANTONIOLI, C. M.; GASPARELLO, E. A.; DONEDA, I. Utilização de Lactobacillus casei e cultura iniciadora na obtenção de iogurte suplementado com inulina e oligrofrutose. Boletim do Centro de Pesquisa e Processamento de Alimentos, v. 24, n. 1, p. 83-98, 2006.

GIBSON, G. R.; ROBERFROID, M. B. Dietary modulation of the human colonic microbiota: introducing the concept of prebiotics. Journal of Nutrition, v. 125, p. 1401-1412, 1995.

GOMES, A. M. P.; MALCATA, F. X. Agentes Probióticos em Alimentos: Aspectos Fisiológicos e Terapêuticos, e Aplicações Tecnológicas. Boletim de Biotecnologia, n. 64, p. 12-22, 1999.

GONZALEZ, N. J.; ADHIKARI, K.; SANCHO-MADRIZ, M. F. Sensory characteristics of peach-flavored yogurt drinks containing prebiotics and synbiotics. LWT - Food Science and Technology, v. 44, n. 1, p. 158-163, 2011.

HUSSAIN, I.; RAHMAN, A.; ATKINSON, N. Quality Comparison of Probiotic and Natural Yogurt. Pakistan Journal of Nutrition, v. 8, n. 1, p. 9 - 12, 2009. http://dx.doi.org/10.3923/pjn.2009.9.12

IAL - INSTITUTO ADOLFO LUTZ. Normas Analíticas do Instituto Adolfo Lutz. $3^{\circ}$ ed. v. 1. São Paulo, 2005.

KEMPKA, A. P.; KRÜGER, R. L.; VALDUGA, E.; DI LUCCIO, M.; TREICHELI, H.; CANSIAN, R.; OLIVEIRA, D. Formulação de bebida láctea fermentada sabor pêssego utilizando substratos alternativos e cultura probiótica. Ciência Tecnologia de Alimentos, v. 28, p. 170-177, 2008. http://dx.doi.org/10.1590/S0101-20612008000500027 
KRISTO, E.; BILIADERIS, C. G.; TZANETAKIS, N. Modelling of the acidification process and rheological properties of milk fermented with a yogurt starter culture using response surface methodology. Food Chemistry, v. 83 , p. 437 446, 2003a. http://dx.doi.org/10.1016/S0308-8146(03)00126-2

KRISTO, E.; BILIADERIS, C. G.; TZANETAKIS, N. Modelling of rheological, microbiological and acidification properties of a fermented milk product containing a probiotic strain of Lactobacillus paracasei. International Dairy Journal, v. 13, p. 517 - 528, 2003b. http://dx.doi.org/10.1016/S0958-6946(03)00074-8

MARTIN, A. F. Armazenamento do iogurte comercial e o efeito na proporção das bactérias láticas. Piracicaba, 2002. 50f. Dissertação (Mestrado em Ciências) - Escola Superior de Agricultura "Luis de Queiros" - Universidade de São Paulo.

MILKPOINT. Disponível em: <http://www.milkpoint.com.br/estatisticas/producao_mundial.htm>. Acesso em 07 de out. 2011.

OLIVEIRA, L. B.; JURKIEWICZ, C. H. Influência de inulina e goma acácia na viabilidade de bactérias probióticas em leite fermentado simbiótico. Brazilian Journal of Food Technology, v. 12, n. 2, p. 138-144, 2009. http://dx.doi.org/10.4260/BJFT20095808

OLIVEIRA, M. N. Tecnologia de Produtos Lácteos Funcionais. São Paulo: Editora Atheneu, 2009.

OLIVEIRA, M. N.; SIVIERI, K.; ALEGRO, A. J. H.; SAAD, I. S. M. Aspectos tecnológicos de alimentos funcionais contendo probióticos. Revista Brasileira de Ciências Farmacêuticas, v. 38, n. 1, p. 1-21, 2002. http://dx.doi.org/10.1590/S1516-93322002000100002

PEREIRA, M. A. G. Efeito do teor de lactose e do tipo de cultura na acidificação e pós-acidificação de iogurtes. Campinas, 2002. 86f. Dissertação (Mestrado em Tecnologia de Alimentos) - Faculdade de Engenharia de Alimentos Universidade Estadual de Campinas.

RENSIS, C. M. V. B.; SOUZA, P. F. F. Análise sensorial de iogurtes light elaborados com adição de fibras de inulina e oligofrutose. Fazu em Revista, n. 5, p. 68 - 72, 2008.

RODAS, M. A. B.; RODRIGUES, R. M. M. S.; SAKUMA, H.; TAVARES, L. Z.; SGARBI, C. R.; LOPES, W. C. C. Caracterização Físico-Química, Histológica e Viabilidade de Bactérias Lácticas em Iogurtes com Frutas. Ciência e Tecnologia de Alimentos, v. 21, n. 3, p. 304 - 309, 2001. http://dx.doi.org/10.1590/S0101-20612001000300009

SAAD, S. M. I. Probióticos e prebióticos: o estado da arte. Revista Brasileira de Ciências Farmacêuticas. v. 42, n. 1, p. 1-16, 2006. http://dx.doi.org/10.1590/S1516-93322006000100002

SANDERS, M. E. Overview of functional foods: emphasis on probiotic bacteria. International Dairy Journal, v. 8, p. 341- 347, 1998. http://dx.doi.org/10.1016/S0958-6946 (98)00056-9

SILVA, S. V. Desenvolvimento de iogurte probiótico com prebiótico. Santa Maria, 2007. 106f. Dissertação (Mestrado em Ciência e Tecnologia dos Alimentos) - Centro de Ciências Rurais - Universidade Federal de Santa Maria.

TORRES, E. A. F. S. Alimentos em questão: uma abordagem técnica para as dúvidas mais comuns. São Paulo: Ponto Crítico, 2001.

TORRES, E. A. F. S.; CAMPOS, N. C.; DUARTE, M.; GARBELOTTI, M. L.; PHILIPPI, S. T.; RODRIGUES, M. R. S. Composição Centesimal e Valor Calórico de Alimentos de Origem Animal. Ciência e Tecnologia de Alimentos, v. 20, n. 2, 2000.

TRONCO, V. M. Manual para inspeção da qualidade do leite. 3. ed. Santa Maria: Ed. UFSM, 2008. 203p.

Submetido em 10 mar. 2012, Aceito para publicação em 20 dez. 2013. 